\title{
Islet pericytes convert into profibrotic myofibroblasts in a mouse model of islet vascular fibrosis
}

\author{
Luciana Mateus Gonçalves $^{1,2}$. Elizabeth Pereira ${ }^{1,3} \cdot$ João Pedro Werneck de Castro ${ }^{1}$ E Ernesto Bernal-Mizrachi ${ }^{1,4}$. \\ Joana Almaça ${ }^{1}$
}

Received: 2 January 2020 / Accepted: 2 April 2020 / Published online: 18 May 2020

(C) Springer-Verlag GmbH Germany, part of Springer Nature 2020

\begin{abstract}
Aims/hypothesis Islet vascular fibrosis may play an important role in the progression of type 2 diabetes, but there are no mouse models allowing detailed mechanistic studies to understand how a dysfunctional islet microvasculature contributes to diabetes pathogenesis. Here we report that the transgenic AktTg mouse, unlike other mouse strains, shows an increased deposition of extracellular matrix (ECM) proteins in perivascular regions, allowing us to study the cellular mechanisms that lead to islet vascular fibrosis.

Methods Using immunohistochemistry, we labelled the islet microvasculature and ECM in pancreas sections of AktTg mice and human donors and performed lineage tracing to follow the fate of islet pericytes. We compared islet microvascular responses in living pancreas slices from wild-type and $A k t T g$ mice.

Results We found that vascular pericytes proliferate extensively, convert into profibrotic myofibroblasts and substantially contribute to vascular fibrosis in the AktTg mouse model. The increased deposition of collagen I, fibronectin and periostin within the islet is associated with diminished islet perfusion as well as impaired capillary responses to noradrenaline (norepinephrine) and to high glucose in living pancreas slices.

Conclusions/interpretation Our study thus illustrates how the AktTg mouse serves to elucidate a cellular mechanism in the development of islet vascular fibrosis, namely a change in pericyte phenotype that leads to vascular dysfunction. Because beta cells in the $A k t T g$ mouse are more numerous and larger, and secrete more insulin, in future studies we will test the role beta cell secretory products play in determining the phenotype of pericytes and other cells residing in the islet microenvironment under physiological and pathophysiological conditions.
\end{abstract}

Keywords Extracellular matrix $\cdot$ Fibrosis $\cdot$ Hyperinsulinaemia $\cdot$ Microvasculature $\cdot$ Myofibroblast $\cdot$ Pancreatic islet $\cdot$ Pericyte

Electronic supplementary material The online version of this article (https://doi.org/10.1007/s00125-020-05168-7) contains peer-reviewed but unedited supplementary material, which is available to authorised users.

Joana Almaça

jalmaca@med.miami.edu

1 Division of Endocrinology, Diabetes and Metabolism, Department of Medicine, University of Miami Miller School of Medicine, Miami, FL 33136, USA

2 Obesity and Comorbidities Research Center, Department of Structural and Functional Biology, Institute of Biology, University of Campinas, Campinas, SP, Brazil

3 Department of Physiology and Biophysics, Miller School of Medicine, University of Miami, Miami, FL, USA

4 Miami VA Health Care System, Miami, FL 33136, USA

\section{Abbreviations}

aSMA $\quad \alpha$ Smooth muscle actin

AktTg Transgenic mice expressing constitutively active Akt1 in beta cells

ECM Extracellular matrix

ERK Extracellular signal-regulated kinase

MAPK Mitogen-activated protein kinase

NG2 Neuron-glial antigen 2

PDGFR $\beta \quad$ Platelet-derived growth factor receptor- $\beta$

PECAM Platelet endothelial cell adhesion molecule

\section{Introduction}

Pancreatic islets are highly vascularised endocrine miniorgans that regulate glucose homeostasis [1]. Their dense 


\section{Research in context}

\section{What is already known about this subject?}

- Vascular fibrosis is a common lesion in islets of people with type 2 diabetes, associated with cytoarchitectural defects and a reduction of beta cell mass

- Significant differences in the islet microvasculature and extracellular matrix exist between mice and humans

- Pericytes are pluripotent and postnatal undifferentiated cells that can adopt various phenotypes

\section{What is the key question?}

- What are the specific cellular mechanisms that promote islet vascular fibrosis in type 2 diabetes?

What are the new findings?

- A transgenic mouse model of beta cell expansion, the AktTg mouse, shows reduced islet blood vessel density and increased deposition of extracellular matrix in perivascular regions

- In AktTg mice, vascular pericytes proliferate extensively, convert into profibrotic myofibroblasts and contribute to islet vascular fibrosis

- Vascular fibrosis is associated with diminished islet blood perfusion and impaired capillary responses

\section{How might this impact on clinical practice in the foreseeable future?}

- Our study suggests that beta cells can affect the phenotype of pericytes and other cells in the islet microenvironment; therapeutic strategies aimed at increasing beta cell mass and function should therefore consider the impact they may have on the islet vascular niche

network of blood vessels and extracellular matrix (ECM) are essential to maintain endocrine cell survival and function [2]. Islets in people with type 2 diabetes are characterised by vascular fibrosis consisting of an excessive deposition of ECM proteins around islet blood vessels [3]. Although it is not central to current models of diabetes pathogenesis [4], earlier studies suggested that islet vascular fibrosis plays an important role in the pathogenesis of type 2 diabetes [5]. Vascular fibrosis could lead to defective hormone secretion either by causing cytoarchitectural defects and reducing beta cell mass [6-10] or by compromising microvascular function, causing vascular leakage [11] and interfering with exchanges between endocrine cells and the blood [12, 13]. Little is known, however, about the specific cellular and molecular mechanisms that promote islet vascular fibrosis in type 2 diabetes. Unfortunately, there is a lack of adequate model organisms allowing detailed mechanistic studies to understand how a dysfunctional islet microvasculature contributes to diabetes pathogenesis.

The mouse is widely used to study islet biology and diabetes pathogenesis because it can be manipulated to establish causal relationships. However, important aspects of the microvasculature and the local extracellular microenvironment of the human islet are not modelled in the mouse. The human islet has fewer and shorter blood vessels, with smaller vessel diameters and reduced vessel branching than mouse islets [14, 15]. There are major differences in the composition of the basement membrane [16], including a dense accumulation of collagen around the microvasculature in the human islet [[17]; Fig. 1). A caveat to these comparisons is that they are made mostly to the C57BL/6 mouse, which may not be the best choice to study islet vascular biology and the local microenvironment. We searched for a mouse model for studying pathophysiological changes in the islet microvasculature and found the AktTg mouse: a transgenic mouse model of beta cell expansion, whose beta cell mass is significantly higher than in wild-type animals owing to enhanced beta cell hyperplasia and hypertrophy [18]. Importantly, islets from these mice showed an increased deposition of ECM proteins in perivascular regions, allowing us to study cellular mechanisms leading to vascular fibrosis in the islet.

Given their pluripotent and postnatal undifferentiated nature, vascular pericytes can adopt various phenotypes. For instance, pericytes can convert into myofibroblasts in fibrotic diseases in different tissues [19-23]. Pericytes at the islet border (endocrine-exocrine interface) have been shown to adopt a myofibroblast-like appearance in rat models of type 2 diabetes and hypertension [13, 24]. We therefore hypothesised that, in the $A k t T g$ mouse, pericytes contribute to vascular fibrosis by becoming profibrotic myofibroblasts. We used cell lineage tracing to follow the fate of islet pericytes and assessed the functional consequences of the anatomical alterations of the islet microvasculature using living mouse pancreas slices. 

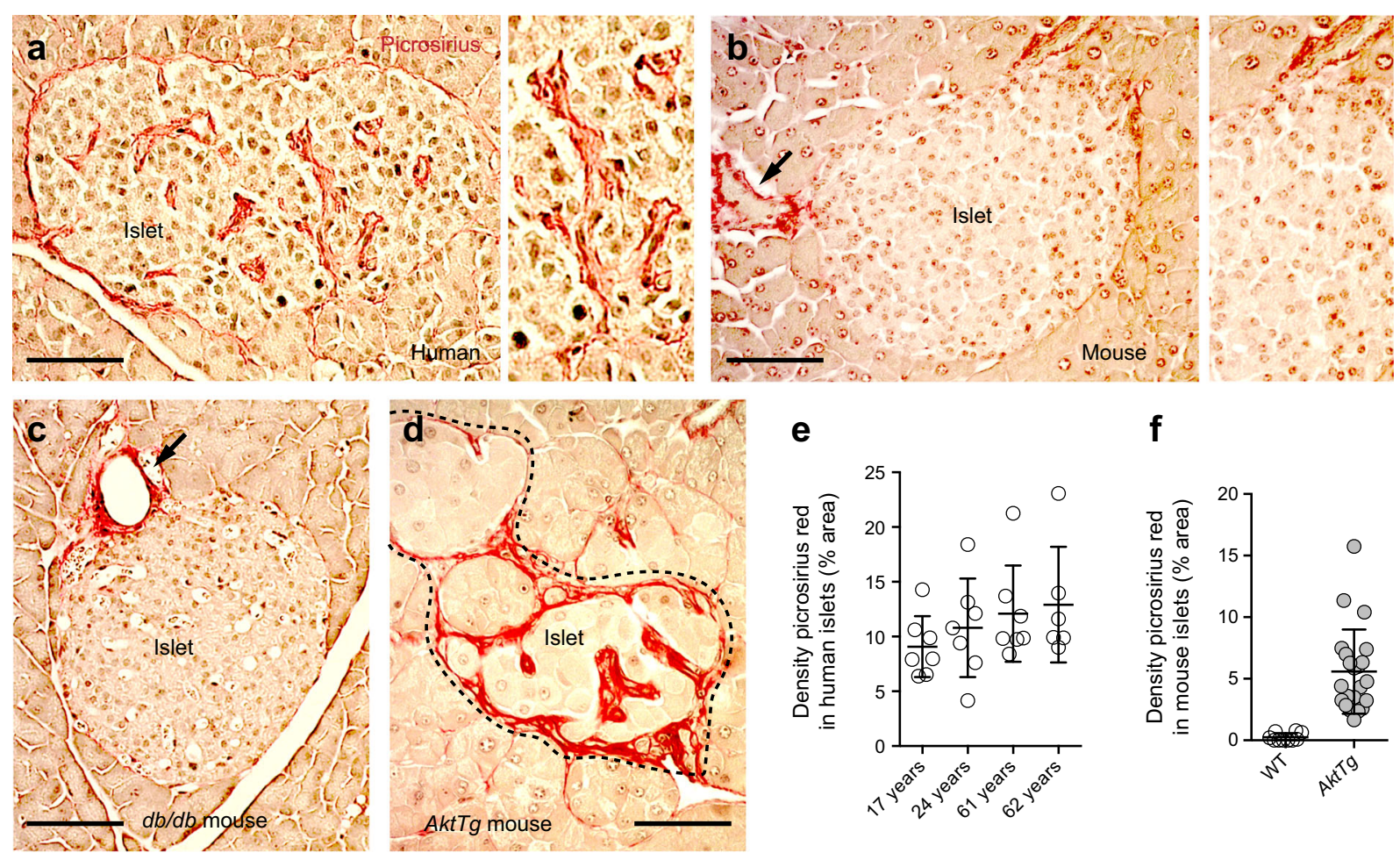

e

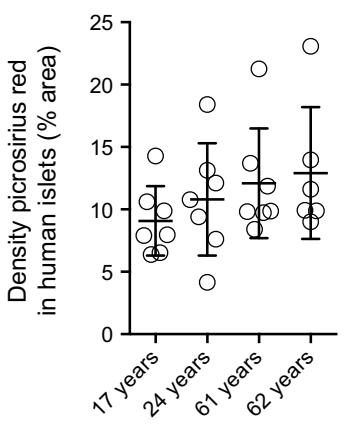

f

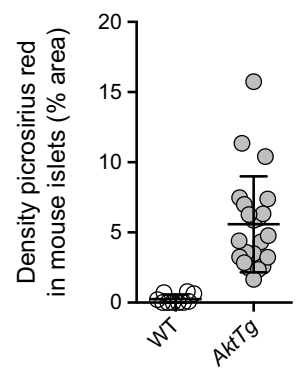

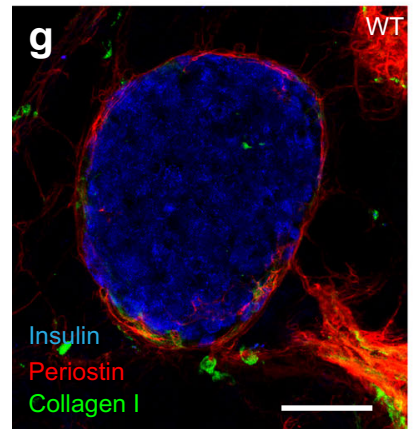

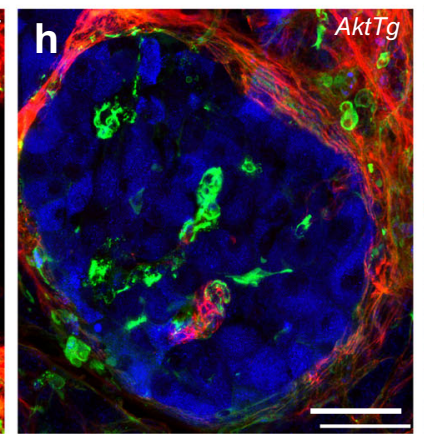

Fig. 1 Perivascular accumulation of ECM in the AktTg transgenic mouse. (a-d) Representative images of islets in the pancreas of a non-diabetic human donor (17 years old; a), a C57BL/6 wild-type mouse (b), a $d b / d b$ mouse (c) and an AktTg mouse (d), stained with the histology dye picrosirius red (red), which specifically stains collagens in tissue sections [25]. When visualised with polarised light, collagen fibres had a bright yellow or orange colour, suggesting it was mostly collagen type I (ESM Fig. 1). Young (3-4 months old) C57BL/6 wild-type, $d b / d b$ and $A k t T g$ mice were used. (e) Quantification of the area labelled with picrosirius red divided by the total islet area (shown as \%; mean $\pm \mathrm{SD}$ ) in islets in pancreatic sections from non-diabetic human donors with different ages; each data point is an islet. (f) Quantification of the area labelled with picrosirius red in wild-type (WT) and $A k t T g$ islets divided by the total islet area (shown as \%; mean $\pm \mathrm{SD} ; n=3-5$ islets/mouse, 3 mice per genotype). (g, h) Representative maximal projections of confocal images of islets from C57BL/ 6 wild-type mouse and $A k t T g$ mouse (3 months old)
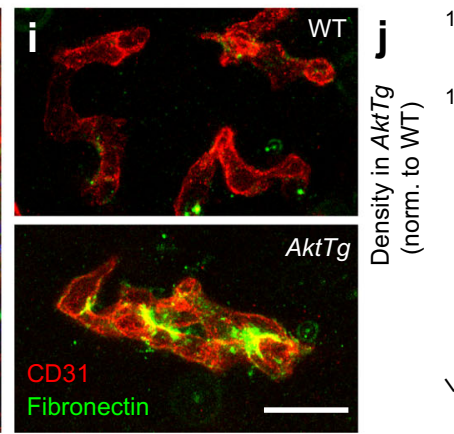

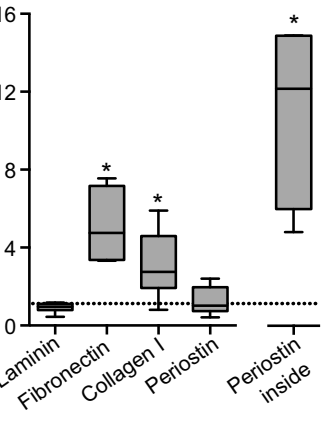

immunostained for insulin (blue), collagen type I (green) and periostin (red). Collagen I and periostin can be visualised in the AktTg islet parenchyma. (i) Representative maximal projections of confocal images of blood vessels in islets from wild-type and $A k t T g$ mice immunostained for CD31 (PECAM, endothelial cell marker, red) and fibronectin (green). (j) Box and whisker plots showing the quantification of the islet area immunostained with antibodies against extracellular matrix proteins laminin, fibronectin, collagen type I and periostin divided by the total islet area, normalised (norm.) to the density of the same proteins in wild-type islets. 'Periostin inside' is the density of periostin within the islet parenchyma, i.e. excluding the interface between endocrine and exocrine compartments (capsule). $* p<0.05$ (one-sample $t$ test using as theoretical mean the value of 1 , indicated with the horizontal dashed line; $n=3-5$ islets/mouse, 3 mice per genotype). Scale bars, $50 \mu \mathrm{m}(\mathbf{a}-\mathbf{d}), 20 \mu \mathrm{m}(\mathbf{g}, \mathbf{h})$ and $10 \mu \mathrm{m}$ (i)

Mice All the experiments were performed with 3-4 month old female and male mice, on a C57BL/6 background. AktTg mice were generated as previously described and bred in house [18]. All other mouse lines were from the Jackson Laboratory (USA). For lineage tracing experiments, we 
crossed male mice that expressed the fluorescent reporter tdTomato (Rosa26-tdTomato, stock no. 012567) with female mice that express Cre recombinase under the Cspg4 promoter (NG2-Cre, stock no. 008533; note that Cspg4 encodes neuron-glial antigen 2 [NG2], which is also known as chondroitin sulphate proteoglycan 4). Cre-positive tdTomato-positive female mice were crossed with $A k t T g$ male mice to yield NG2-tdTomato-AktTg mice. Mice harbouring a spontaneous mutation in the leptin receptor ( $d b / d b$ mice; stock no. 000697) were also used. To label proliferating cells, BrdU $(1 \mathrm{mg} / \mathrm{ml})$ was added to the drinking water for 21 days. All experiments were conducted according to protocols approved by the University of Miami Institutional Animal Care and Use Committee.

Organ donors Human pancreas tissue sections were obtained from the Histology Core of the Diabetes Research Institute of the University of Miami. Information about human organ donors is included in ESM Table 1. Experiments were approved by the responsible ethics committee of the University of Miami.

Picrosirius red staining Picrosirius red stain in combination with polarisation microscopy was used to visualise collagen in tissue sections [25]. Pancreatic sections $(10 \mu \mathrm{m})$ from wildtype, $d b / d b$ and AktTg mice and human donors were deparaffinised in xylene and rehydrated in ethanol series before incubation with picrosirius red solution $(0.5 \mathrm{~g}$ of Direct red 80 in $500 \mathrm{ml}$ of saturated aqueous solution of picric acid) for $60 \mathrm{~min}$. The sections were washed twice with acidified water $(5 \mathrm{ml}$ acetic acid (glacial) in 1 litre water), dehydrated and mounted. Slides were observed under a microscope (BX41, Olympus, USA) equipped with polarised light and images analysed with ImageJ software (http://imagej.nih. gov/ij/). The density of picrosirius red staining was calculated by dividing the area of red-stained structures within the islet parenchyma by the islet area. Quantification was performed in a blind fashion.

Preparation of living pancreatic slices Pancreatic slices (150 $\mu \mathrm{m}$ thickness) were prepared from wild-type and $\mathrm{AktTg}$ mice (3-4 months old) as previously described [26]. Slices were incubated in HEPES-buffered solution containing $3 \mathrm{mmol} / \mathrm{l}$ glucose. For blood vessel labelling, Lycopersicon esculentum lectin conjugated to DyLight 594 (DL-1177, Vector Labs, USA) was injected $(75 \mu \mathrm{g})$ in the tail vein $10 \mathrm{~min}$ before sacrificing.

Confocal imaging of living pancreatic slices Living pancreatic slices of wild-type and AktTg mice were imaged on a Leica SP5 upright confocal microscope (Leica Microsystems, Germany) using a $\times 40$ water immersion objective [26]. Slices were continuously perfused with HEPES-buffered solution containing $3 \mathrm{mmol} / \mathrm{l}$ glucose. DyLight 594-labelled tomato lectin was excited at $594 \mathrm{~nm}$ and emission detected at 610-650 nm. Backscatter light was collected upon excitation with the $633 \mathrm{~nm}$ laser. We recorded changes in blood vessel diameter induced by noradrenaline (norepinephrine) $(20 \mu \mathrm{mol} / \mathrm{l})$, basal glucose solution $(3 \mathrm{mmol} / \mathrm{l})$, or by high glucose $(16 \mathrm{mmol} / \mathrm{l})$. To estimate the percentage of the islet microvasculature that was functional, we used ImageJ to quantify, in maximal projections of the islet, the area labelled with the lectin and divided it by the total islet blood vessel area (immunostained with an antibody against CD31). Quantification of islet blood vessel diameter was done as previously described [26]. Briefly, in confocal images of the islet, we drew a straight line transversal to the blood vessel borders and used the 'reslice' $\mathrm{z}$-function in ImageJ to generate a single image showing the changes in vessel diameter over time [27]. We drew another line on the resliced image and, using the 'plot profile' function, we determined the position of the pixels with the highest fluorescence intensity and considered these the vessel borders. Vessel diameter was calculated by subtracting these two position values. Only one islet was imaged in each slice.

Immunohistochemistry In this study we used 3-4 month old wild-type and $A k t T g$ mice of both sexes $(n=3)$. Mice were perfused with $4 \%$ PFA and the pancreases collected in tubes containing $4 \%$ PFA. Small pieces of human pancreatic tissue were fixed overnight with $4 \%$ PFA. Tissues were cryoprotected in a sucrose gradient and frozen in optimal cutting temperature compound (OCT) before cryosectioning. Immunohistochemistry was performed as previously described [26] and antibodies used can be found in the ESM Methods. We used ImageJ to estimate in confocal planes the numbers of pericytes and endothelial cells by manually counting the number of nuclei surrounded by cytoplasmic NG2 or CD31 immunostaining, divided by the islet area and multiplied by a mean area of $10,000 \mu \mathrm{m}^{2}$. To determine vessel and ECM protein densities, in maximal projection images, we divided total immunostained area by the islet area (visualised with insulin staining). To determine colocalisation between tdTomato (red channel) and pericytes, myofibroblast markers and ECM proteins (green channel), we used the ImageJ plugin 'intensity correlation analysis' and calculated Mander's colocalisation coefficients (M1 and M2). Quantifications were performed in a blind fashion.

Quantitative real-time PCR Pancreatic islets were isolated from NG2-tdTomato wild-type mice ( $\sim 7$ months old) and viable tdTomato-positive and negative cells were FACS sorted from cell suspensions. Quantitative real-time PCR was performed as described in the ESM Methods to determine the expression of the following genes: Rn18s, Cspg4 (which encodes NG2), Acta2, Pdgfrb. 
Statistics We used GraphPad Prism 5.0 and performed Student's $t$ test, one-sample $t$ test or one-way ANOVA followed by a Tukey's multiple comparison test. We considered statistical significance when $p<0.05$. All data were assessed to ensure normal distribution and equal variance between groups. Throughout the manuscript we present data as mean \pm SEM, unless otherwise stated in the figure legend.

\section{Results}

A mouse model of islet vascular fibrosis The microvasculature of the human islet differs from that of the mouse islet $[14,15]$. In particular, the human islet is characterised by an accumulation of collagen fibres around its blood vessels [16, 17]. When we used the picrosirius red dye to specifically label collagen in pancreas sections, we found that the human islet microvasculature was outlined by the red staining (Fig. 1). Strikingly, already at a young age (17 years), $\sim 10 \%$ of the human islet area contained picrosirius red-labelled connective tissue, a percentage that did not significantly increase with age (Fig. 1a,e). The islet microvasculature of wild-type C57BL/6 mouse, by contrast, was not stained at all (Fig. 1b,f). There were picrosirius red-labelled structures outside the mouse islet (e.g. connective tissue around acini, ducts and major blood vessels; Fig. 1b). Older C57BL/6 mice and $d b / d b$ mice also did not show signs of islet vascular fibrosis (Fig. 1c). When we inspected the pancreas of the $A k t T g$ mouse, however, we found that there was intense picrosirius red labelling within the islet parenchyma, that appeared mostly as bright yellow or orange fibres upon polarised light (Fig. 1d,f and ESM Fig. 1).

The AktTg mouse is a transgenic mouse model of beta cell expansion [18]. This mouse has increased Akt activity in beta cells due to the expression of a constitutively active Akt1 $(\mathrm{PKB} \alpha)$ mutant under the control of the insulin gene promoter. Beta cell mass is significantly greater than in wild-type animals owing to enhanced beta cell proliferation and hypertrophy, yielding much higher fasting and fed plasma insulin levels and improved glucose tolerance, while maintaining normoglycaemia ([18], ESM Fig. 2). In this context of beta cell expansion, we not only detected abundant vascular fibrosis with picrosirius red in $A k t T g$ islets (Fig. 1d,f), but also found increased type I collagen and fibronectin immunostaining within the islet (Fig. 1g-j). Laminin density was not different between islets from wild-type C57BL/6 mice and those from $A k t T g$ mice. Perivascular regions in $A k t T g$ islets were further labelled for periostin, a myofibroblast marker and a secreted ECM protein that is involved in cellular adhesion and organisation of collagen [28] (Fig. 1h,j). Therefore, we took advantage of these changes and used the Akt Tg mouse to study pathophysiological mechanisms associated with islet vascular fibrosis.
Altered islet microvasculature in islets from AktTg mice In view of the increased islet vascular fibrosis in the $A k t T g$ mouse model, we then examined the islet microvasculature and its cellular components: endothelial cells and pericytes. Pericytes were immunostained with two bona fide pericyte markers, NG2 and platelet-derived growth factor receptor- $\beta$ (PDGFR $\beta$ ) [26]. Endothelial cells were either labelled with a fluorescent lectin from Lycopersicon esculentum (Fig. 2a) or immunostained with an antibody against the endothelial cell marker CD31 (also known as platelet endothelial cell adhesion molecule [PECAM]; Fig. 2b). We determined major alterations of the islet capillary network and pericyte coverage in AktTg mice (Fig. 2). While in wild-type mice the islet capillary network was more dense than in the surrounding exocrine tissue ([29]; Fig. 2a,c), islets from AktTg mice exhibited fewer blood vessels (Fig. 2a,c). The typical tube morphology of capillaries made of a layer of endothelial cells covered with pericytes was disrupted in $A k t T g$ islets (Fig. 2b). Blood vessels in $A k t T g$ islets had significantly more pericytes and endothelial cells (Fig. 2b-e). Wild-type islets displayed a 1:3 ratio of pericytes:endothelial cells, consistent with our previously reported ratio in mouse pancreatic islets ([26]; Fig. 2f). In contrast, $A k t T g$ islets showed a higher pericyte:endothelial cell ratio ( 1:2; Fig. 2 f). The morphology of blood vessels in the acinar tissue surrounding islets of $A k t T g$ mice was conserved (Fig. 2a,b). These results indicate that in the AktTg mouse the increased fibrosis is associated with changes in the structure and composition of the islet microvasculature.

\section{Pericytes are activated and proliferate in islets from $A k t T g$} mice To assess the contribution of proliferation to the increase in endothelial cell and pericyte numbers, we performed BrdU experiments. Consistent with published data [18], higher beta cell proliferation was observed in $A k t T g$ transgenic mice (ESM Fig. 2). Interestingly, approximately $60 \%$ of NG2positive islet pericytes incorporated BrdU in AktTg mice, suggesting that the increase in pericyte number in $A k t T g$ islets was due to increased proliferation (Fig. 3a,d). The percentage of proliferating NG2-positive pericytes in $A k t T g$ mice was significantly higher than that of all the other cell populations analysed (Fig. $3 \mathrm{~d}$ ): insulin-positive beta cells, CD31-positive endothelial cells, $\alpha$ smooth muscle actin $(\alpha \mathrm{SMA})$-positive cells (smooth muscle, myofibroblasts, pancreatic stellate cells; [30]), PDGFR $\beta$-positive pericytes/fibroblasts (Fig. 3b,d). There were also more proliferating PDGFR $\beta$-positive pericytes in AktTg than in wild-type mouse islets (Figs $2 \mathrm{~g}$, 3c,d and ESM Fig. 3).

We then assessed the magnitude of activation of critical pathways known to promote growth and proliferation: the Akt and mitogen-activated protein kinase (MAPK)/extracellular signal-regulated kinase (ERK) signalling pathways. We used antibodies that recognise phosphorylated (active) Akt (pAkt, Ser 473) and phospho-p44/42 MAPK (ERK1/2) 

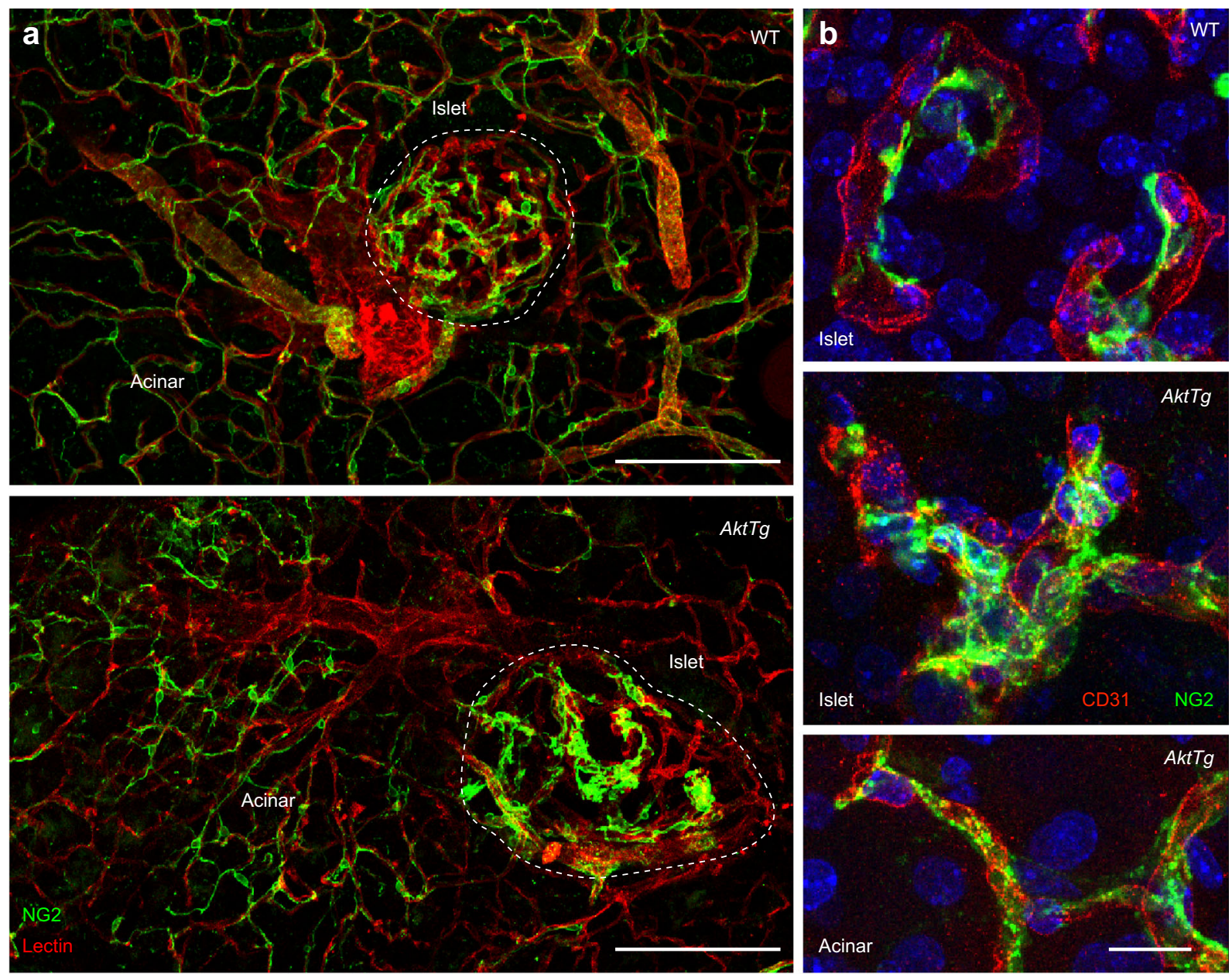

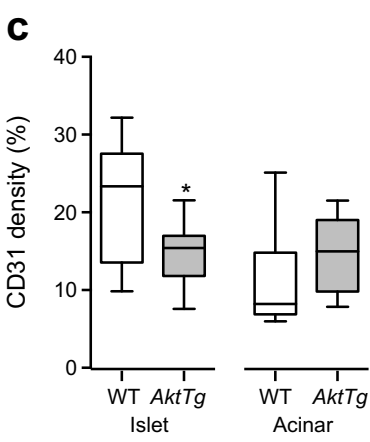

d

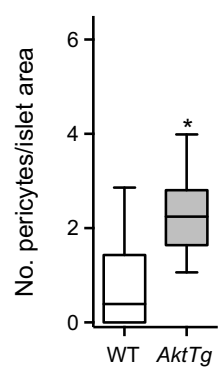

Fig. 2 Altered islet microvasculature in islets from AktTg mice. (a) Representative maximal projections of confocal images of pancreases from C57BL/6 wild-type (WT) and Akt Tg mice showing blood vessels covered with pericytes. Blood vessels were labelled with a fluorescent lectin from Lycopersicon esculentum (red) and pericytes immunostained for NG2 (green). Increased pericyte coverage of AktTg islet capillaries is visible. Pericyte coverage of blood vessels in the acinar tissue in $\mathrm{AktTg}$ mice is apparently similar to that of wild-type acinar tissue. (b) Representative maximal projections of confocal images of blood vessels in islets from wild-type and $A k t T g$ mice showing pericytes and endothelial cells immunostained, respectively, for NG2 (green) and for CD31 (PECAM, red). Cell nuclei were labelled with DAPI (blue). Pericytes nicely cover capillaries in wild-type islets but their coverage is increased in AktTg islets. Pericytes and capillaries in the acinar tissue of AktTg mice are not different from wild-type acinar vessels. (c) Quantification of the area covered with blood vessels (immunostained with an anti-CD31
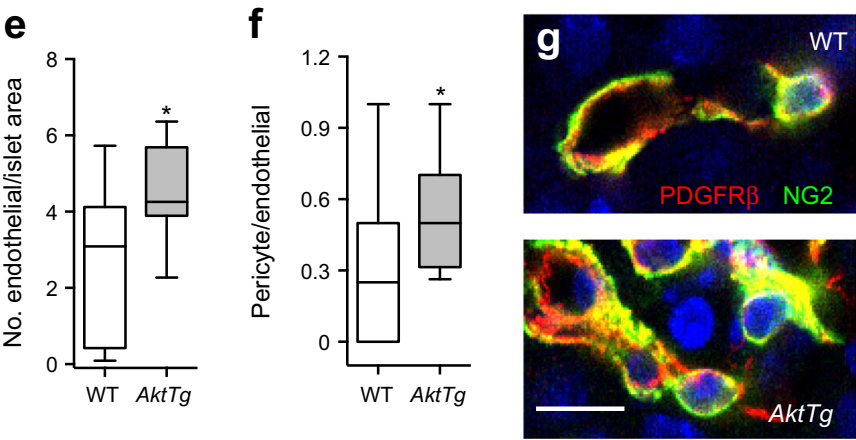

antibody) in islets and surrounding acinar tissue in wild-type and $A k t T g$ pancreases, divided by the total area (shown as \%). $* p<0.05$ (unpaired $t$ test; $n=3-5$ islets/mouse, 3 mice per genotype). (d, e) Quantification of the total number of (d) NG2-labelled pericytes, or (e) CD31-labelled endothelial cells in confocal sections of islets from wild-type and $\mathrm{AktTg}$ mice, divided by the islet area and multiplied by a mean islet area of $10,000 \mu \mathrm{m}^{2} .{ }^{*} p<0.05$ (unpaired $t$ test; $n=3$ confocal planes/islet, 5 islets/mouse, 3 mice per genotype). (f) Quantification of the ratio of pericyte number to endothelial cell number in confocal sections of wildtype and $A k t T g$ islets. * $p<0.05$ (unpaired $t$ test; $n=3$ confocal planes/ islet, 5 islets/mouse, 3 mice per genotype). (g) Representative maximal projections of confocal images of pericytes in wild-type and $A k t T g$ islets showing pericytes immunostained for NG2 (green) and PDGFR $\beta$ (red). Increased number of pericytes are present in AktTg islets. Scale bars, $100 \mu \mathrm{m}(\mathbf{a})$ and $10 \mu \mathrm{m}(\mathbf{b}, \mathbf{g})$ 

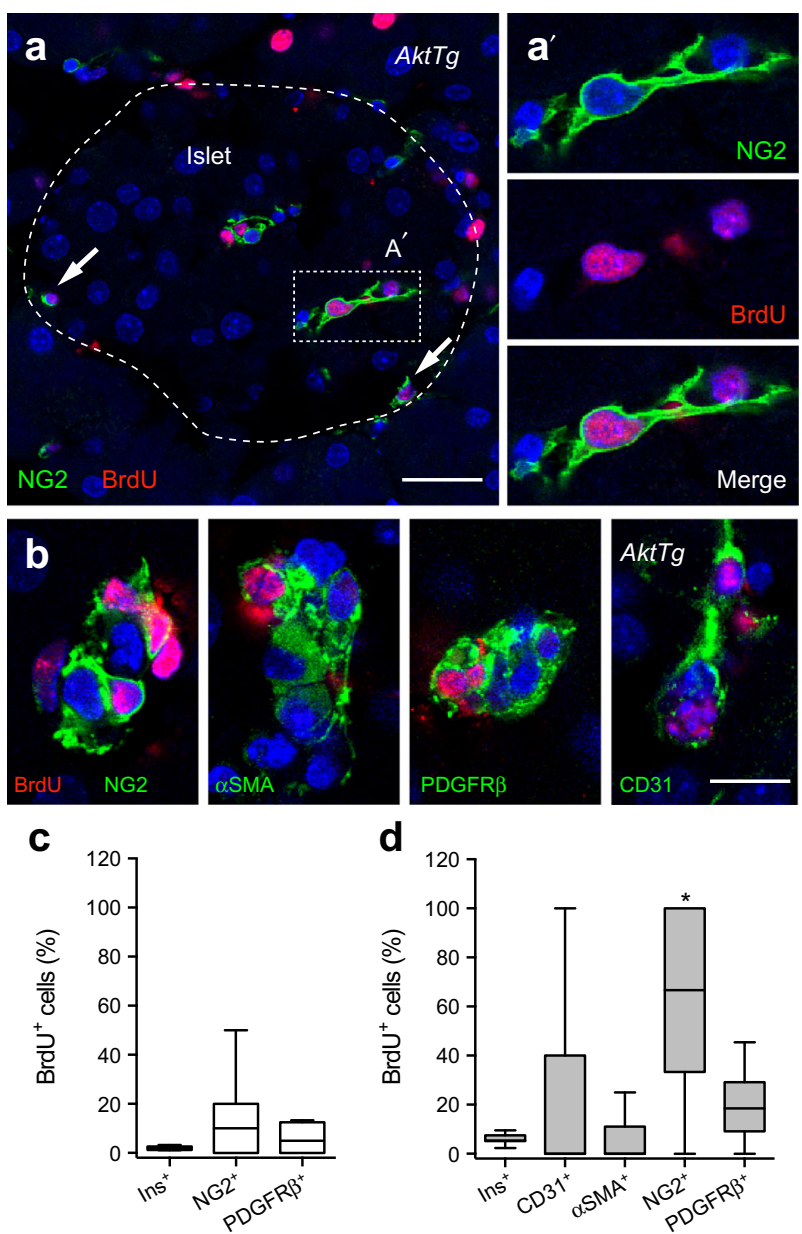

Fig. 3 Increased pericyte proliferation in islets from $A k t T g$ mice. (a) Representative confocal image of an $A k t T g$ islet immunostained for NG2 (pericytes, green) and BrdU (red). The arrows indicate proliferating pericytes (BrdU-positive); the dashed line shows the islet border. $\left(\mathbf{a}^{\prime}\right)$ Zoomed image of the region within the dashed rectangle shown in (a) of a pericyte that incorporated BrdU. (b) Representative confocal images of blood vessels within AktTg islets immunostained for BrdU (red) and NG2, $\alpha$ SMA, PDGFR $\beta$ or CD31 (green). Images of entire islets are shown in ESM Fig. 3. (c, d) Quantification of the percentage of insulinpositive beta cells $\left(\mathrm{Ins}^{+}\right), \mathrm{NG} 2$-positive pericytes and PDGFR $\beta$-positive pericytes/fibroblasts that incorporated BrdU in wild-type (c) and $A k t T g$ islets (d). We also determined the percentage of proliferating CD31-positive endothelial cells and $\alpha$ SMA-positive mural cells/myofibroblasts in Akt Tg islets. The percentage of $\mathrm{NG}^{+} \mathrm{BrdU}^{+} / \mathrm{NG}^{+}$cells was significantly different from all the other proliferating cell populations $(* p<0.05$, oneway ANOVA followed by a Tukey's multiple comparisons test; $n=3$ confocal planes/islet, 5 islets/mouse, 3 mice/genotype). Scale bars, $20 \mu \mathrm{m}(\mathbf{a})$ and $10 \mu \mathrm{m}(\mathbf{b})$

(Thr 202/Tyr 204). While low levels of pAkt were detected in pancreatic sections from wild-type mice, strong pAkt immunoreactivity was observed in AktTg islets (ESM Fig. 4). In Akt Tg islets, pAkt was detected at higher levels in endocrine cells. pAkt fluorescence intensity was also significantly higher in pericytes from $A k t T g$ islets than in pericytes in wild-type islets. pERK fluorescence could be detected in endocrine and vascular cells in wild-type islets, but its intensity significantly decreased in endocrine cells while remaining high in pericytes
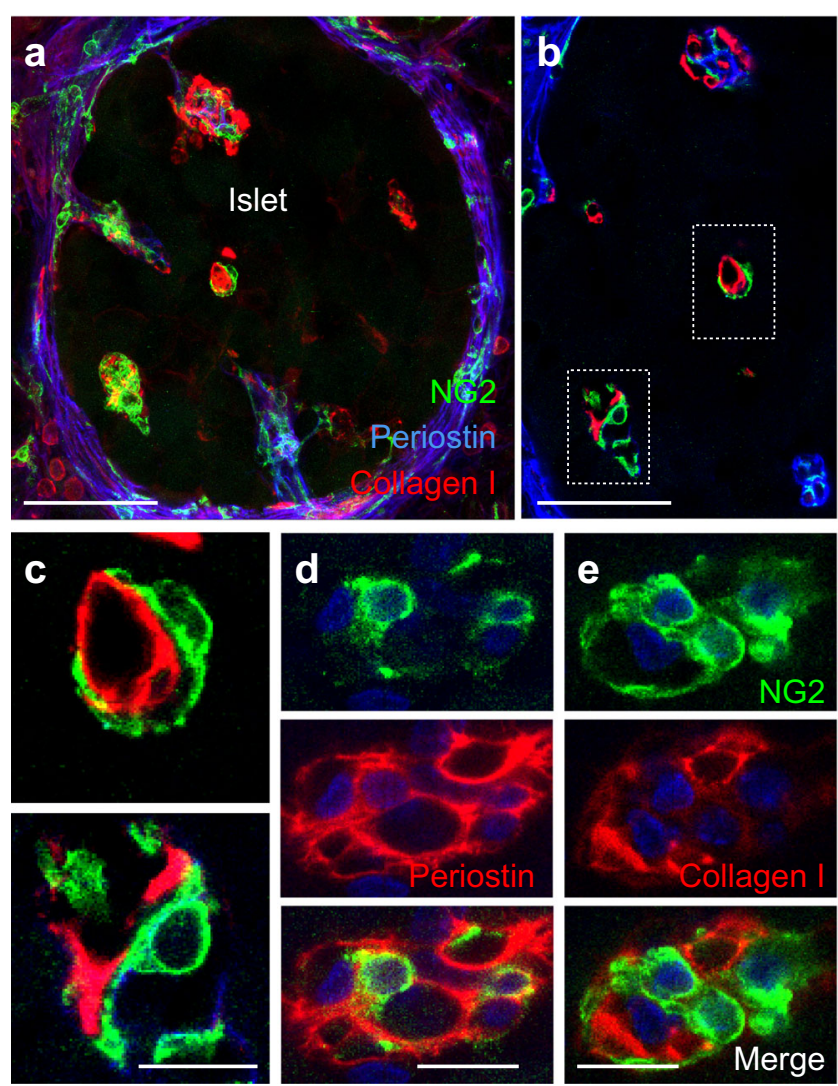

Fig. 4 Pericytes associate with collagen type I and express periostin in $A k t T g$ islets. (a) Representative maximal projection of confocal images of an $A k t T g$ islet showing pericytes (NG2, green) in the vicinity of collagen type I (red) and the matricellular protein and myofibroblast marker periostin (blue). (b, c) Representative confocal images of islet pericytes (green) in an AktTg islet in close association with collagen type I (red). (c) Zoomed images of regions within dashed boxes shown in (b). (d, e) Representative confocal images of islet pericytes (NG2, green) and periostin (red, d) or collagen I immunostaining (red, e). Merged images are shown underneath. These images are representative of 5 islets/mouse, 3 mice/genotype. Scale bars, $20 \mu \mathrm{m}(\mathbf{a}, \mathbf{b})$ and $10 \mu \mathrm{m}(\mathbf{c}-\mathbf{e})$

in islets from $A k t T g$ mice (ESM Fig. 4). Indeed, islet pericytes and exocrine tissue exhibited the highest levels of pERK immunoreactivity in pancreatic sections from $A k t T g$ mice.

A subset of pericytes in AktTg islets differentiates into myofibroblasts Pericytes are critical for microvascular homeostasis but, owing to their pluripotent and undifferentiated nature, pericytes can differentiate into myofibroblasts in progressive fibrotic diseases [19-22]. Myofibroblasts are the major source of extracellular matrix proteins that accumulate in tissue fibrosis. To determine if islet pericytes contribute to vascular fibrosis in $A k t T g$ islets, we first used immunostaining to assess the localisation of pericytes in relation to those of the matrix proteins collagen type I and periostin (Fig. 4). Extracellular collagen type I deposits around the microvasculature in $\mathrm{AktTg}$ islets were always found in close association with NG2-labelled pericytes, whose cytoplasmic processes seemed to wrap and surround these ECM aggregates (Fig. 

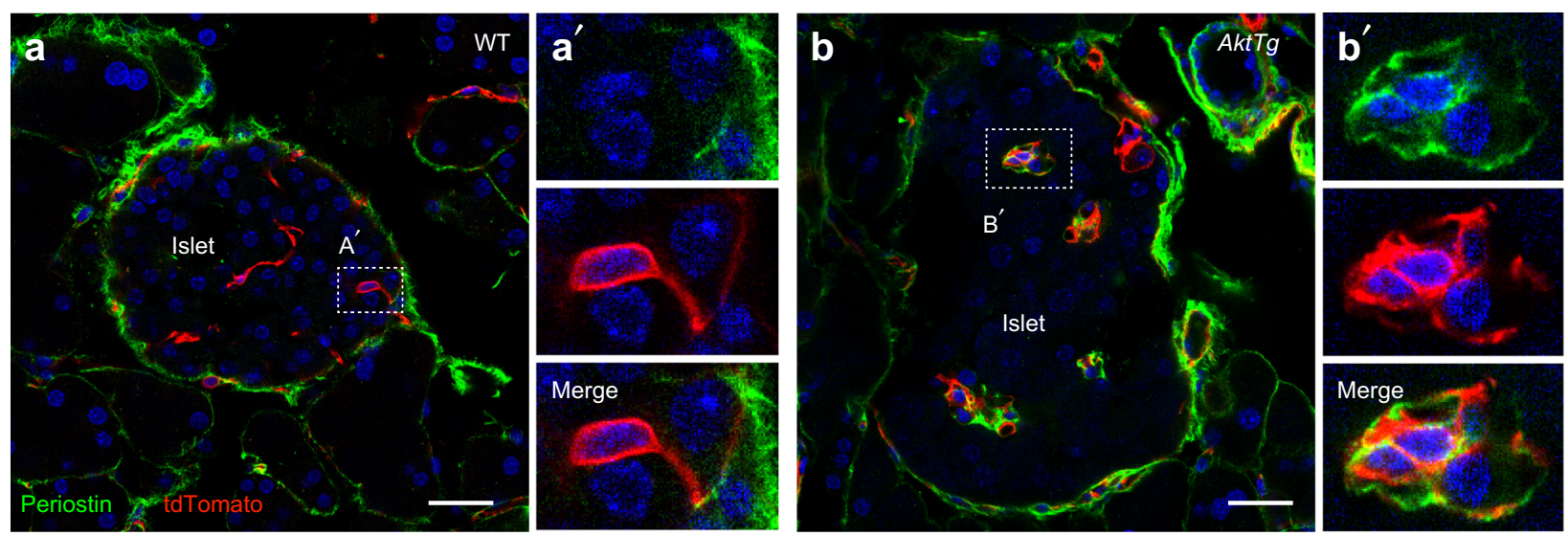

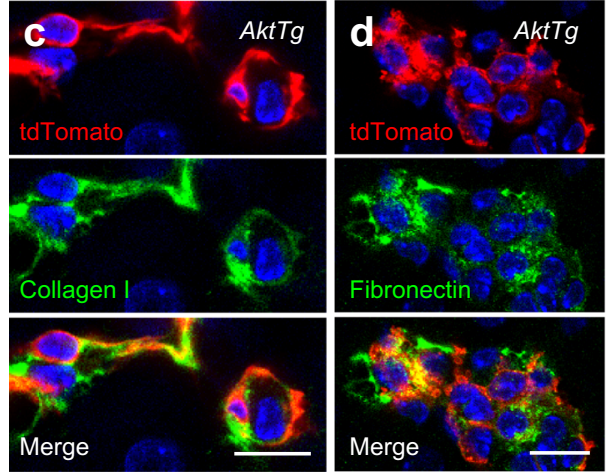

Fig. 5 A subset of pericytes in $A k t T g$ islets differentiates into myofibroblasts. (a, b) Representative confocal images of an NG2tdTomato wild-type islet (WT, a) and NG2-tdTomato- $A k t T g$ islet $(A k t T g, \mathbf{b})$ showing tdTomato-labelled pericytes and periostin immunostaining (green). Cell nuclei are shown in blue. ( $\mathbf{a}^{\prime}$ and $\mathbf{b}^{\prime}$ ) Higher magnification images of regions within dashed boxes. In wild-type islets, periostin is present in the interface between endocrine/exocrine tissue but not expressed by pericytes, while tdTomato-labelled pericytes in $A k t T g$ islets express periostin. (c, d) Representative confocal images of regions in islets from NG2-tdTomato- $A k t T g$ mice showing tdTomato-

4b-e). Pericytes labelled for the myofibroblast marker periostin were found in close association with this ECM protein (Fig. 4d). These data suggest that islet pericytes could contribute to the pool of profibrotic myofibroblasts in $\mathrm{AktTg}$ mice. Interestingly, pericytes in islets in pancreas sections from young non-diabetic individuals also express periostin and associate closely with collagen type I (ESM Fig. 5).

To determine the potential contribution of the pericyte population to the pool of profibrotic myofibroblasts, we performed lineage tracing studies by crossing a fluorescent reporter tdTomato mouse to mice expressing Cre recombinase under the Cspg4 promoter (NG2-tdTomato mice). In these mice, vascular smooth muscle cells and pericytes express the reporter in peripheral tissues such as pancreatic islets (Fig. 5e and ESM Fig. 6; [26]). To validate the specificity of our Cre model, we sorted tdTomato-positive cells from NG2tdTomato mice. As an internal control, we also collected tdTomato-negative cells. tdTomato-positive cells were indeed pericytes as shown by the increased levels of pericyte genes labelled pericytes and collagen type I (green, c) and fibronectin immunostaining (green, d). Cell nuclei are shown in blue. tdTomato-labelled pericytes synthesising collagen I and fibronectin can be seen, as well as accumulation of these ECM proteins in their extracellular space. (e) Quantification of the fraction of tdTomato-positive cells that express the pericytic markers NG2, PDGFR $\beta$ and $\alpha$ SMA, ECM proteins fibronectin and collagen type I, and (myo)fibroblast markers vimentin and periostin in wild-type (white) and NG2-tdTomato-AktTg mice (grey). * $p<0.05$ (unpaired $t$ test; $n=3$ confocal planes/islet, 5 islets/mouse, 2 mice/genotype). Scale bars, $20 \mu \mathrm{m}(\mathbf{a}, \mathbf{b})$ and $10 \mu \mathrm{m}(\mathbf{c}, \mathbf{d})$

Cspg4 (which encodes NG2), Pdgfrb and Acta2 (which encodes $\alpha \mathrm{SMA}$ ) in these cells compared with tdTomatonegative cells (ESM Fig. 6).

To study changes in the pericyte phenotype in the AktTg mouse, NG2-tdTomato mice were transferred to the AktTg background to yield NG2-tdTomato- $A k t T g$ mice. NG2tdTomato-AktTg mice showed higher plasma insulin levels, hypercellularity of vascular cells (ESM Fig. 6) and excessive perivascular ECM deposition typical of the $\mathrm{Akt} T \mathrm{~g}$ background. Approximately $90 \%$ of tdTomato-positive cells were NG2-positive or PDGFR $\beta$-positive mural cells in wild-type and $A k t T g$ islets, further confirming the specificity of the NG2-Cre model (Fig. 5e and ESM Fig. 6). A subset of lineage-traced tdTomato-positive cells was also labelled for $\alpha \mathrm{SMA}$, fibronectin and collagen type I in both wild-type and AktTg mice (Fig. 5c,e). Within the lineage-traced population of pericytes in islets from $A k t T g$ mice we found significant increases in the incidence of fibronectin labelled cells as well as de novo expression of fibroblast markers vimentin and 

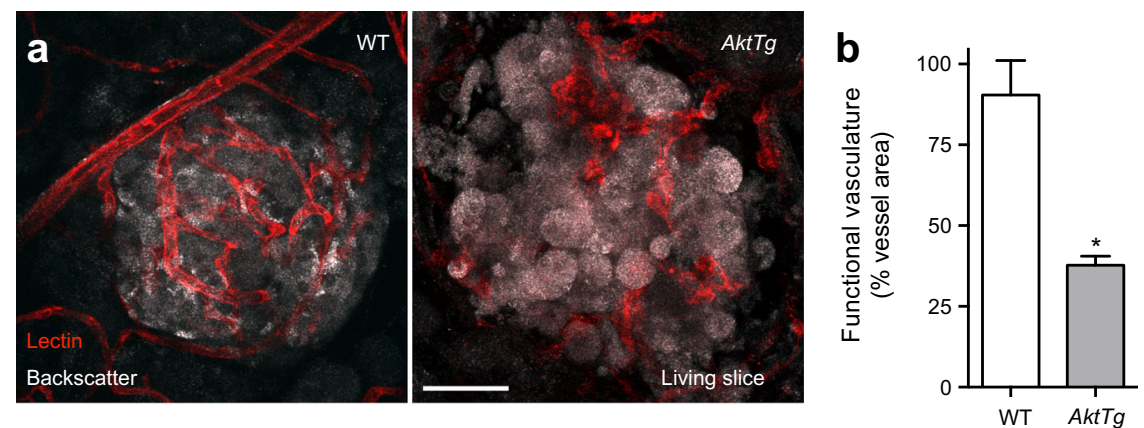

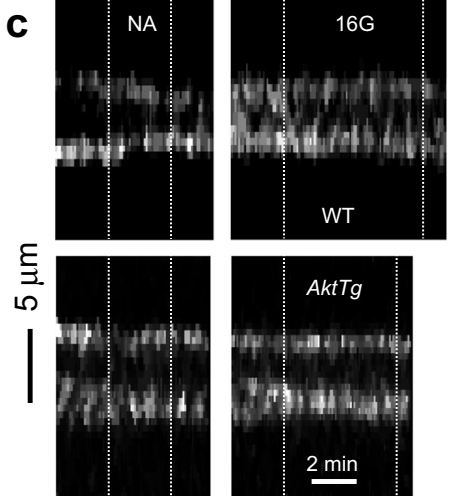

Fig. 6 Impaired vascular perfusion and microvessel responses in $\mathrm{AktTg}$ islets ex vivo. (a) Representative maximal projections of confocal images of islets in living pancreatic slices from wild-type (WT) and AktTg mice. Blood vessels were labelled with an intravascular injection of fluorescent Lycopersicon esculentum lectin (red) $10 \mathrm{~min}$ before euthanising the animals. Endocrine cells in the islet can be visualised because of their higher backscatter signal (grey). Scale bar, $50 \mu \mathrm{m}$. (b) Quantification of the area of blood vessels that were labelled upon lectin injection (functional vasculature) as percentage of total islet vessel area. $* p<0.05$ (unpaired $t$ test). (c) Temporal projections of line scans perpendicular to the vessel axis showing temporal patterns of changes in vessel diameter (see Methods). Capillary borders can be seen in white. Vertical white dashed lines indicate when the stimuli were present. Stimuli used were noradrenaline (NA; $20 \mu \mathrm{mol} / \mathrm{l}$ in $3 \mathrm{mmol} / \mathrm{l}$ glucose) and high glucose $(16 \mathrm{G} ; 16 \mathrm{mmol} / \mathrm{l}$ glucose). Noradrenaline induced a strong constriction

periostin (Fig. 5a-e). These results indicate that pericytes give rise to profibrotic myofibroblasts in $A k t T g$ islets.

Myofibroblasts are a heterogenous cell population with different cellular origins. Of the periostin- and $\alpha$ SMApositive cell populations in the islets of AktTg mice, $69 \pm 3 \%$ and $40 \pm 3 \%$ were tdTomato-positive, respectively. These data suggest that a subset of islet myofibroblasts $(\sim 30-60 \%)$ may originate from cell populations other than pericytes, such as pancreatic stellate cells [31]. Nevertheless, islet pericytes contribute a substantial fraction of islet myofibroblasts in AktTg mice.

Impaired vascular perfusion and microvessel responses in AktTg islets ex vivo To examine the functional consequences of the changes in islet pericytes and ECM in the AktTg model, we adapted the pancreatic slice technique to examine in situ responses of the fibrotic microvessels in their native environment $[26,32]$. In living pancreatic tissue slices, the different
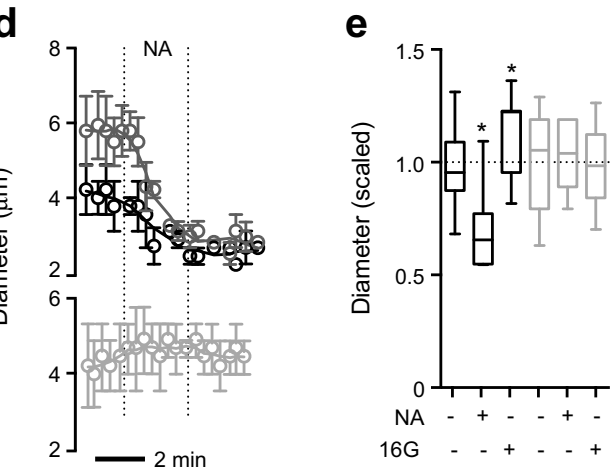

of the wild-type islet capillary and high glucose dilated it. AktTg capillaries did not respond to the stimuli applied. (d) Traces of responses as in (c) show the mean change in vessel diameter induced by noradrenaline application (black symbols, capillaries in wild-type islets; dark grey symbols, wild-type arterioles; light grey symbols, capillaries in AktTg islets; $n=3-4$ vessels per group). Vertical dotted lines indicate the time noradrenaline is present. (e) Quantification of changes induced by noradrenaline and high glucose in capillary diameter based on temporal projections as shown in (c). Black bars (wild-type) and grey bars (AktTg). Values were scaled to the initial diameter (before drug application, $3 \mathrm{mmol} / \mathrm{l}$ glucose). Only $\sim 20 \%$ of islet capillaries responded upon stimulation. $* p<0.05$ (one-sample $t$ test using as theoretical mean the value of 1 as diameter values were scaled to the initial diameter, indicated with the horizontal dashed line; $n=3-4$ vessels per group, 3 slices/mouse, 3 mice/genotype)

tissue components are preserved allowing the study of interactions between endocrine cells, vascular cells, fibroblasts and other cell compartments. To assess the functionality of the islet microvasculature, we labelled blood vessels with an intravenous injection of a fluorescent lectin from Lycopersicon esculentum (Fig. 6a). There was a $\sim 60 \%$ reduction in perfusion of AktTg islet, calculated as the percentage of the islet blood vessel area that was labelled with the lectin (functional vasculature; Fig. 6b). We then assessed whether the abnormalities in perfusion were associated with impaired responses to known capillary vasodilators and vasoconstrictors. In line with our published results [26], a subset of capillaries in wild-type mouse islets constricted upon noradrenaline stimulation $(20 \mu \mathrm{mol} / \mathrm{l}$; approximately $30 \%$ decrease in diameter) and dilated upon beta cell stimulation with high glucose (16 mmol/1; approximately 15\% increase in diameter; Fig. $6 \mathrm{c}-\mathrm{e})$. Noradrenaline also elicited a powerful constriction of the feeding arteriole in wild-type islets (Fig. 6d, dark grey 
trace). In contrast, capillaries in $A k t T g$ islets were neither responsive to the vasoconstrictor noradrenaline nor to high glucose (Fig. 6c-e). Lack of responses of AktTg islet capillaries was not due to poor tissue viability as endocrine cells in AktTg islets still responded to $\mathrm{KCl}$ depolarisation (ESM Fig. 7). These data indicate that phenotypical alterations of pericytes and increased ECM accumulation around $A k t T g$ islet capillaries impair microvascular function. Islet microvascular dysfunction could be the cause of impaired insulin secretion per beta cell unit of $A k t T g$ mice in response to glucose in vivo (ESM Fig. 2d, [33]).

\section{Discussion}

Our results show that the $A k t T g$ mouse had substantial alterations of the islet microvasculature and ECM. In particular, blood vessel density in $A k t T g$ islets was lower than in wildtype mouse islets and the number of pericytes increased 2.5fold, yielding a higher pericyte:endothelial cell ratio. In addition, the density of different ECM proteins in perivascular regions was significantly greater in $A k t T g$ islets, and a subset of islet pericytes converted into myofibroblasts and participated in increased ECM synthesis in this transgenic mouse model.

Our lineage tracing data show that pericytes in the islet parenchyma are capable of differentiating into myofibroblasts and are actively involved in ECM synthesis, similar to their role in fibrotic diseases in different tissues [19-23]. Our results are in line with a previous study in a rat model of type 2 diabetes, the human islet amyloid polypeptide rat, where a pericyte synthesising fibrillar collagen was observed at the interface between the endocrine and exocrine pancreas [13]. Interestingly, only a subset (approximately 40\%) of islet pericytes adopted a myofibroblast-like phenotype, consistent with the notion that pericytes are a very heterogeneous cell population [34]. Future studies will focus on identifying the cellular and molecular mechanisms that promote the expansion and differentiation of individual subsets of pericytes. Differential interaction with resident macrophages or with other recruited immune cells could determine whether or not they adopt a profibrotic phenotype [35, 36].

Given the higher beta cell mass and secretory activity, it is likely that islet pericytes in $A k t T g$ mice are abnormally exposed to beta cell secretory products that could affect their phenotype. Insulin, for instance, is a potent mitogenic peptide that controls cellular growth, proliferation, differentiation and migration. Insulin has been shown to stimulate the proliferation and growth of endothelial cells and pericytes in the retina $[37,38]$. In addition, insulin also stimulates the proliferation of pancreatic stellate cells and the production of ECM proteins through a robust and sustained activation of $\mathrm{Akt} / \mathrm{mammalian}$ target of rapamycin (mTOR) [39] or angiotensin II type 2 signalling pathways [40]. In our study we observed activation of Akt and MAPK/ERK signalling pathways in pericytes in AktTg islets (ESM Fig. 4). Both pathways are downstream of the insulin receptor, suggesting that pericytes could indeed be responding to higher levels of insulin. Future studies will determine whether insulin receptor activation is involved in the phenotypical change of the subset of islet pericytes that converts into myofibroblasts.

Excessive beta cell secretory activity could affect pericytes and the ECM by additional indirect mechanisms. Several beta cell secretory products are highly proinflammatory and could potentially activate myofibroblasts [41, 42]. For instance, ATP that is co-released with insulin is a strong activator of islet and acinar macrophages [32]. In addition, vascular endothelial growth factor A (VEGFA) released by beta cells leads to endothelial cell proliferation, thickening of the basement membrane of islet blood vessels, progressive macrophage infiltration, and proinflammatory cytokine production [43]. The potentially inflammatory environment in AktTg islets could also activate other subpopulations of myofibroblasts not derived from pericytes, such as pancreatic stellate cells [44]. These myofibroblast-like cells are usually found in the exocrine pancreas but are also present in pancreatic islets and their numbers increase in type 2 diabetic rats [31].

Endocrine cells in pancreatic islets depend on their blood vessels for proper function, and defects in the islet microvasculature can lead to diabetic phenotypes [45] However, because longitudinal and interventional studies are not possible in human beings, it is not known what happens at this vascular niche during the progression of type 2 diabetes. For instance, excessive deposition of ECM proteins around islet blood vessels has been described as the most frequent lesion in the islets of people with type 2 diabetes $[3,5]$ but neither the causes nor the functional consequences of islet vascular fibrosis have been fully elucidated. It has been suggested that the excessive deposition of connective tissue in perivascular regions in the islets could compromise capillary responses and the exchanges between beta cells and the circulation resulting in defective hormone secretion $[12,13]$. Here we show that changes in pericyte coverage and perivascular fibrosis in AktTg islets lower the percentage of functional microvasculature and impair capillary responses to noradrenaline and glucose. These alterations have functional consequences. Indeed, when corrected for the significant increase in beta cell mass in AktTg mice, in vivo insulin secretion in response to glucose is impaired in transgenic animals (ESM Fig. 2d). Similar findings were previously reported by Tuttle and colleagues when they measured insulin secretion from in situ perfused pancreases of $A k t T g$ mice [33]. These data support a potential negative impact of islet vascular fibrosis and chronic microvascular dysfunction on beta cell function. However, how acute, dynamic changes of islet microvascular function and blood flow impact hormone secretion still remains to be determined. 
It is now clear that the function of pericytes goes beyond their role as mural cells of the microcirculation. Given their location at the interface between the blood and the islet parenchyma, pericytes are in a unique position to coordinate changes in the microenvironment with islet blood flow and perfusion and, ultimately, modulate islet hormone secretion. Pericytes can directly control islet perfusion and blood vessel function by actively modulating islet capillary diameter [26], or indirectly, by acquiring a myofibroblast-like phenotype and contributing to ECM synthesis as we show here. Excessive perivascular accumulation of ECM can result in deranged architecture and islet cell death, as well as impair microvascular function, leading, ultimately, to islet dysfunction. Using the AktTg mouse model, we now can conduct studies aimed at elucidating the role of insulin or other beta cell secretory products in determining the number, phenotype and function of islet pericytes. Elucidating the crosstalk between pericytes and beta cells is necessary to fully understand the pathogenesis of islet adaptation in diabetes.

Acknowledgements The authors thank R. Barro Soria and A. Caicedo for carefully reviewing the manuscript, K. Johnson for histological work, J. Camperio and M. Canales for data quantification, and O. Umland for helping with FACS sorting pericytes (University of Miami).

Data availability Data presented in this manuscript are available upon request from the authors.

Funding This work was funded by NIH grants K01DK111757 (JA), R01DK073716 (EBM) and DK084236 (EBM), as well as by the NIDDK-supported Human Islet Research Network (HIRN, RRID:SCR 014393; https://hirnetwork.org; UC4 DK104162, New Investigator Pilot Award to JA).

Authors' relationships and activities The authors declare that there are no relationships or activities that might bias, or be perceived to bias, their work.

Contribution statement JA and EBM designed the study; LMG, EP, JPWC and JA performed experiments; LMG and JA analysed data; EP and JPWC analysed and interpreted data; JA and EBM wrote the manuscript. All authors revised the manuscript and approved its final version. JA is the guarantor of this work.

\section{References}

1. Brunicardi FC, Stagner J, Bonner-Weir S et al (1996) Microcirculation of the islets of Langerhans. Long Beach Veterans Administration Regional Medical Education Center Symposium. Diabetes 45(4):385-392. https://doi.org/10.2337/ diab.45.4.385

2. Nikolova G, Jabs N, Konstantinova I et al (2006) The vascular basement membrane: a niche for insulin gene expression and $\beta$ cell proliferation. Dev Cell 10(3):397-405. https://doi.org/10.1016/j. devcel.2006.01.015

3. Gepts W (1957) Contribution to the morphological study of the islands of Langerhans in diabetes; study of the quantitative variations of the different insular constituents. Ann Soc R Sci Med Nat Brux 10(1):5-108 [article in French]

4. Halban PA, Polonsky KS, Bowden DW et al (2014) $\beta$-Cell failure in type 2 diabetes: postulated mechanisms and prospects for prevention and treatment. Diabetes Care 37(6):1751-1758. https://doi.org/ $10.2337 / \mathrm{dc} 14-0396$

5. Gepts W, Lecompte PM (1981) The pancreatic islets in diabetes. Am J Med 70(1):105-115. https://doi.org/10.1016/0002-9343(81) 90417-4

6. Portha B, Lacraz G, Kergoat M et al (2009) The GK rat beta-cell: a prototype for the diseased human beta-cell in type 2 diabetes? Mol Cell Endocrinol 297(1-2):73-85. https://doi.org/10.1016/j.mce. 2008.06.013

7. Ko SH, Kwon HS, Kim SR et al (2004) Ramipril treatment suppresses islet fibrosis in Otsuka Long-Evans Tokushima fatty rats. Biochem Biophys Res Commun 316(1):114-122. https://doi. org/10.1016/j.bbrc.2004.02.023

8. Movassat J, Saulnier C, Serradas P, Portha B (1997) Impaired development of pancreatic beta-cell mass is a primary event during the progression to diabetes in the GK rat. Diabetologia 40(8):916925. https://doi.org/10.1007/s001250050768

9. Shima K, Shi K, Sano T, Iwami T, Mizuno A, Noma Y (1993) Is exercise training effective in preventing diabetes mellitus in the Otsuka-Long-Evans-Tokushima fatty rat, a model of spontaneous non-insulin-dependent diabetes mellitus? Metab Clin Exp 42(8): 971-977. https://doi.org/10.1016/0026-0495(93)90009-d

10. Mizuno A, Noma Y, Kuwajima M, Murakami T, Zhu M, Shima K (1999) Changes in islet capillary angioarchitecture coincide with impaired B-cell function but not with insulin resistance in male Otsuka-Long-Evans-Tokushima fatty rats: dimorphism of the diabetic phenotype at an advanced age. Metab Clin Exp 48(4): 477-483. https://doi.org/10.1016/S0026-0495(99)90107-5

11. Heydinger DK, Lacy PE (1974) Islet cell changes in the rat following injection of homogenized islets. Diabetes 23(7):579-582. https://doi.org/10.2337/diab.23.7.579

12. Gepts W (1981) Islet changes in human diabetes. In: Cooperstein SJ, Watkins D (eds) The islet of Langerhans: biochemistry, physiology and pathology. Academic Press, Cambridge MA, pp 321356. https://doi.org/10.1016/B978-0-12-187820-7.50019-X

13. Hayden MR, Karuparthi PR, Habibi J et al (2008) Ultrastructure of islet microcirculation, pericytes and the islet exocrine interface in the HIP rat model of diabetes. Exp Biol Med (Maywood) 233(9): 1109-1123. https://doi.org/10.3181/0709-rm-251

14. Brissova M, Shostak A, Fligner CL et al (2015) Human islets have fewer blood vessels than mouse islets and the density of islet vascular structures is increased in type 2 diabetes. J Histochem Cytochem 63(8):637-645. https://doi.org/10.1369/0022155415573324

15. Cohrs CM, Chen C, Jahn SR et al (2017) Vessel network architecture of adult human islets promotes distinct cell-cell interactions in situ and is altered after transplantation. Endocrinology 158(5): 1373-1385. https://doi.org/10.1210/en.2016-1184

16. Virtanen I, Banerjee M, Palgi J et al (2008) Blood vessels of human islets of Langerhans are surrounded by a double basement membrane. Diabetologia 51(7):1181-1191. https://doi.org/10. 1007/s00125-008-0997-9

17. Van Deijnen JH, Van Suylichem PT, Wolters GH, Van Schilfgaarde R (1994) Distribution of collagens type I, type III and type $\mathrm{V}$ in the pancreas of rat, dog, pig and man. Cell Tissue Res 277(1):115-121. https://doi.org/10.1007/bf00303087

18. Bernal-Mizrachi E, Wen W, Stahlhut S, Welling CM, Permutt MA (2001) Islet $\beta$ cell expression of constitutively active Akt1/PKB $\alpha$ induces striking hypertrophy, hyperplasia, and hyperinsulinemia. $\mathrm{J}$ Clin Invest 108(11):1631-1638. https://doi.org/10.1172/jci13785

19. Dulauroy S, Di Carlo SE, Langa F, Eberl G, Peduto L (2012) Lineage tracing and genetic ablation of $\mathrm{ADAM}_{2} 2^{+}$perivascular cells identify a major source of profibrotic cells during acute tissue 
injury. Nat Med 18(8):1262-1270. https://doi.org/10.1038/nm. 2848

20. Goritz C, Dias DO, Tomilin N, Barbacid M, Shupliakov O, Frisen J (2011) A pericyte origin of spinal cord scar tissue. Science 333(6039):238-242. https://doi.org/10.1126/science.1203165

21. Humphreys BD, Lin SL, Kobayashi A et al (2010) Fate tracing reveals the pericyte and not epithelial origin of myofibroblasts in kidney fibrosis. Am J Pathol 176(1):85-97. https://doi.org/10.2353/ ajpath.2010.090517

22. Lin SL, Kisseleva T, Brenner DA, Duffield JS (2008) Pericytes and perivascular fibroblasts are the primary source of collagenproducing cells in obstructive fibrosis of the kidney. Am J Pathol 173(6):1617-1627. https://doi.org/10.2353/ajpath.2008.080433

23. Schrimpf C, Xin C, Campanholle G et al (2012) Pericyte TIMP3 and ADAMTS1 modulate vascular stability after kidney injury. J Am Soc Nephrol 23(5):868-883. https://doi.org/10.1681/asn. 2011080851

24. Hayden MR, Karuparthi PR, Habibi J et al (2007) Ultrastructural islet study of early fibrosis in the Ren2 rat model of hypertension. Emerging role of the islet pancreatic pericyte-stellate cell. JOP 8(6): 725-738

25. Junqueira LC, Bignolas G, Brentani RR (1979) Picrosirius staining plus polarization microscopy, a specific method for collagen detection in tissue sections. Histochem J 11(4):447-455. https://doi.org/ $10.1007 / \mathrm{bf0} 1002772$

26. Almaca J, Weitz J, Rodriguez-Diaz R, Pereira E, Caicedo A (2018) The pericyte of the pancreatic islet regulates capillary diameter and local blood flow. Cell Metab 27(3):630-644 e634. https://doi.org/ 10.1016/j.cmet.2018.02.016

27. Fischer MJ, Uchida S, Messlinger K (2010) Measurement of meningeal blood vessel diameter in vivo with a plug-in for ImageJ. Microvasc Res 80(2):258-266. https://doi.org/10.1016/j. mvr.2010.04.004

28. Kanisicak O, Khalil H, Ivey MJ et al (2016) Genetic lineage tracing defines myofibroblast origin and function in the injured heart. Nat Commun 7(1):12260. https://doi.org/10.1038/ncomms12260

29. Henderson JR, Moss MC (1985) A morphometric study of the endocrine and exocrine capillaries of the pancreas. Q J Exp Physiol 70(3):347-356. https://doi.org/10.1113/expphysiol.1985. sp002920

30. Bachem MG, Schneider E, Gross H et al (1998) Identification, culture, and characterization of pancreatic stellate cells in rats and humans. Gastroenterology 115(2):421-432. https://doi.org/10. 1016/S0016-5085(98)70209-4

31. Lee E, Ryu GR, Ko SH, Ahn YB, Song KH (2017) A role of pancreatic stellate cells in islet fibrosis and $\beta$-cell dysfunction in type 2 diabetes mellitus. Biochem Biophys Res Commun 485(2): 328-334. https://doi.org/10.1016/j.bbrc.2017.02.082

32. Weitz JR, Makhmutova M, Almaca J et al (2018) Mouse pancreatic islet macrophages use locally released ATP to monitor beta cell activity. Diabetologia 61(1):182-192. https://doi.org/10.1007/ s00125-017-4416-y

33. Tuttle RL, Gill NS, Pugh W et al (2001) Regulation of pancreatic $\beta$ cell growth and survival by the serine/threonine protein kinase Akt1/PKB $\alpha$. Nat Med 7(10):1133-1137. https://doi.org/10.1038/ nm1001-1133

34. Shepro D, Morel NM (1993) Pericyte physiology. FASEB J 7(11): 1031-1038. https://doi.org/10.1096/fasebj.7.11.8370472

35. Koyama Y, Brenner DA (2017) Liver inflammation and fibrosis. J Clin Invest 127(1):55-64. https://doi.org/10.1172/jci88881

36. Shook BA, Wasko RR, Rivera-Gonzalez GC et al (2018) Myofibroblast proliferation and heterogeneity are supported by macrophages during skin repair. Science (New York, NY) 362(6417):2971. https://doi.org/10.1126/science.aar2971

37. King GL, Buzney SM, Kahn CR et al (1983) Differential responsiveness to insulin of endothelial and support cells from micro- and macrovessels. J Clin Invest 71(4):974-979. https://doi.org/10.1172/ jci110852

38. King GL, Goodman AD, Buzney S, Moses A, Kahn CR (1985) Receptors and growth-promoting effects of insulin and insulinlike growth factors on cells from bovine retinal capillaries and aorta. $\mathrm{J}$ Clin Invest 75(3):1028-1036. https://doi.org/10.1172/jci111764

39. Yang J, Waldron RT, Su HY et al (2016) Insulin promotes proliferation and fibrosing responses in activated pancreatic stellate cells. Am J Physiol Gastrointest Liver Physiol 311(4):G675-G687. https://doi.org/10.1152/ajpgi.00251.2016

40. Kim JW, Ko SH, Cho JH et al (2008) Loss of beta-cells with fibrotic islet destruction in type 2 diabetes mellitus. Front Biosci 13(13):6022-6033. https://doi.org/10.2741/3133

41. Donath MY, Boni-Schnetzler M, Ellingsgaard H, Ehses JA (2009) Islet inflammation impairs the pancreatic $\beta$-cell in type 2 diabetes. Physiology (Bethesda) 24(6):325-331. https://doi.org/10.1152/ physiol.00032.2009

42. Wynn TA (2008) Cellular and molecular mechanisms of fibrosis. J Pathol 214(2):199-210. https://doi.org/10.1002/path.2277

43. Agudo J, Ayuso E, Jimenez V et al (2012) Vascular endothelial growth factor-mediated islet hypervascularization and inflammation contribute to progressive reduction of $\beta$-cell mass. Diabetes 61(11):2851-2861. https://doi.org/10.2337/db12-0134

44. Erkan M, Adler G, Apte MV et al (2012) StellaTUM: current consensus and discussion on pancreatic stellate cell research. Gut 61(2):172-178. https://doi.org/10.1136/gutjnl-2011-301220

45. Richards OC, Raines SM, Attie AD (2010) The role of blood vessels, endothelial cells, and vascular pericytes in insulin secretion and peripheral insulin action. Endocr Rev 31(3):343-363. https:// doi.org/10.1210/er.2009-0035

Publisher's note Springer Nature remains neutral with regard to jurisdictional claims in published maps and institutional affiliations. 